\title{
Inhibition of Morphogenesis in a Prokaryote by Cyclic Adenosine $3^{\prime}: 5^{\prime}$-Monophosphate
}

\author{
By CECILIA KIMBERLIN-HARIRI AND J. B. CLARK \\ Botany and Microbiology Department, University of Oklahoma, Norman, \\ Oklahoma 73069, U.S.A.
}

AND R. A. JACOBSON

Chemistry Department, University of Oklahoma

(Received 9 August 1976)

\begin{abstract}
SUMMARY
The morphological sphere-rod-sphere changes in Arthrobacter crystallopoietes were altered by introducing cyclic AMP into the bacteria. The presence of this cyclic AMP delayed both the formation of the bacillus form and the change back into the coccus form. A specific phosphodiesterase inhibitor, theophylline, also delayed the bacillus formation and the final coccus formation. Cyclic GMP had no demonstrable effect.
\end{abstract}

\section{INTRODUCTION}

Arthrobacter crystallopoietes undergoes a morphogenic cycle involving a sphere to rod to phere change in morphology. In the presence of an inducing agent, such as succinate, the cocci elongate to bacilli which change back to cocci at the termination of active growth. If grown in a non-inducing medium, such as glucose mineral salts, growth continues in the coccus form with no morphological change. Luscombe \& Gray (I97I, I974) grew this organism under carefully controlled conditions in a chemostat and concluded that the change from coccus to rod morphology was merely the result of increased growth rate and that no morphogenic cycle was involved. However, there is evidence in the literature which suggests that morphogenesis is involved in this genus (Clark, 1972), and so whether the bacillus form is the result of rapid growth, or the rapid growth is the result of the morphogenic changes associated with bacillary formation, remains to be resolved.

While the functions of cyclic AMP in prokaryotic cells are diverse and numerous (Rickenberg, 1974), morphogenic effects have been demonstrated in relatively few cases. These effects are mostly 'positive' and include such observations as the requirement of cyclic AMP in flagellation in coliforms (Yokota \& Gots, 1970), the induction of fruiting body formation in Myxococcus xanthus (Campos \& Zustman, 1974) and the enhancement of differentiation in Caulobacter crescentus (Shapiro et al., 1972). This paper reports the inhibition of morphogenesis in A. crystallopoietes (Ensign \& Rittenberg, 1963) by cyclic AMP, a 'negative' effect on a morphogenic event, demonstrating diversity in the regulatory roles of cyclic AMP in these prokaryotic systems. In addition, the effect of inhibition of cyclic AMP-specific phosphodiesterase was studied; the observed effects were thought to result from the prevention of cyclic AMP destruction in vivo and thus an increase in intracellular levels. 


\section{METHODS}

Cocci of Arthrobacter crystallopoietes (ATCCI548I) were taken from a synchronous $24 \mathrm{~h}$ culture and treated with Tris/EDTA (Leive, 1965) to render them more permeable to cyclic AMP (Pastan \& Pearlman, 1968). Treated cells were inoculated into flasks containing $0.5 \%$ (w/v) glucose minimal salts medium (GMS) (Ensign \& Wolfe, 1964) in which cells are coccoidal only, and into three media in which cells undergo morphogenesis: $0.5 \%$ (w/v) L-asparagine minimal salts (AMS); $0.5 \%(\mathrm{w} / \mathrm{v})$ succinate minimal salts (SMS); and TGY broth (Baltimore Biological Laboratories). Initial absorbance was standardized to 0.025 at $485 \mathrm{~nm}$. At the time of inoculation and at $2 \mathrm{~h}$ intervals thereafter, cyclic AMP or cyclic GMP (Sigma) was added to maintain cyclic nucleotide concentrations of $0 . \mathrm{I}, 0.5$, $\mathrm{I} \cdot 0,2 \cdot 0$ and $5 \cdot 0 \mathrm{~mm}$. Growth was measured by absorbance at $485 \mathrm{~nm}$ and morphology was determined microscopically using preparations stained with $0.1 \%(w / v)$ methylene blue.

Controls utilized media to which no cyclic nucleotide had been added and media containing nucleotides previously treated with phosphodiesterase. Similar experiments were performed adding $10 \mathrm{~mm}$-theophylline to the four media containing the Tris/EDTA treated cells at various time intervals.

Experiments were repeated using bacteria grown to different stages of the 'life-cycle', i.e. early rods, mid-exponential phase rods and fragmenting rods reverting to cocci. These were treated with Tris/EDTA and reinoculated into their original media which had been titrated from an alkaline $\mathrm{pH}$ to the original $\mathrm{pH}$ of the medium $(7 \cdot 2)$. To these cultures" $5 \cdot 0 \mathrm{~mm}-$ cyclic AMP, 5.0 mM-cyclic GMP or Io mM-theophylline was added and observation of the life-cycle was continued.

\section{RESULTS}

The Tris/EDTA treatment had no effect on the morphogenic cycle but a slightly higher maximum growth was achieved compared with that of untreated control cells. Without this treatment, the cells were apparently impermeable to cyclic AMP and theophylline (Pastan \& Pearlman, 1968). Cyclic GMP did not affect the growth or morphogenesis of treated or untreated cells under any of the conditions used. The morphogenic cycle in the three media is shown in Fig. I. Cells remain coccoidal in the GMS medium only. No effect of cyclic AMP was seen in GMS medium in which cells were coccoidal only, or in any medium in which the cyclic AMP concentration was below $\mathrm{I} \cdot 0 \mathrm{mM}$, or when phosphodiesterase was used to break down the cyclic AMP before it was added to the medium.

With concentrations of I mM-cyclic AMP and above, elongation of the cocci was delayed and rods did not appear until approximately $16 \mathrm{~h}$ (Fig. 2). Fragmentation was also delayed and occurred at 20 to $22 \mathrm{~h}$ as compared to $\mathrm{I} 8$ to $22 \mathrm{~h}$ in the controls. However, if cyclic AMP was not added until after $8 \mathrm{~h}$ growth, it had no observable effects on the "morphogenic cycle'. There are several possible explanations for this loss of effect. The compound could be unstable in the increasingly alkaline media which result during growth, a critical threshold level might have been reached intracellularly, cyclic AMP might be effective for only a short time span, or after $8 \mathrm{~h}$ the cells might no longer be permeable to exogenous cyclic AMP.

To test this last possibility, bacteria were allowed to reach a particular stage in the morphogenic cycle then treated with Tris/EDTA, reinoculated, and cyclic AMP added as described in Methods. These experiments demonstrated that once rod formation had begun exogenous cyclic AMP did not delay the remaining morphogenic stages of fragmentation and reversion to cocci. 
Morphogenic Cycle:

\begin{tabular}{|c|c|c|}
\hline Cocci & Elongation and & Fragmentation and \\
\hline & rod formation & reversion to \\
\hline$\stackrel{\circ}{0}$ & $\underset{5-8 \mathrm{~h}}{O} \underset{8-16 \mathrm{~h}}{\longrightarrow}$ & $\underset{16-18 \mathrm{~h}}{\infty} \underbrace{}_{18-22 \mathrm{~h}} 000$ \\
\hline
\end{tabular}

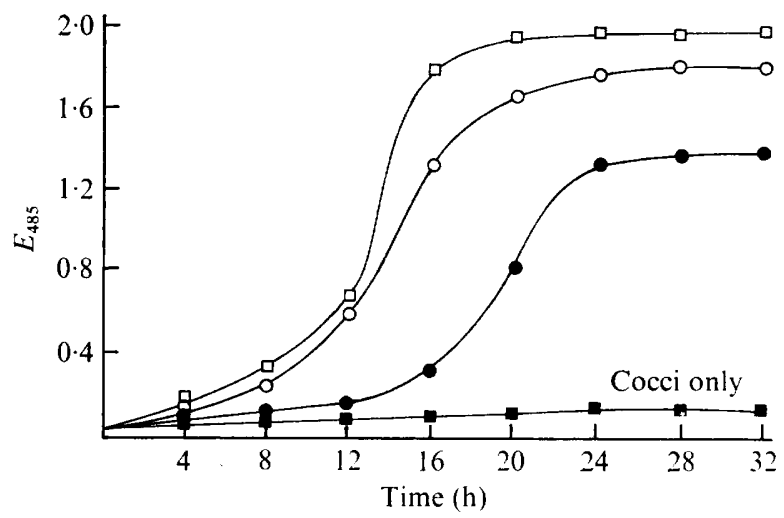

Fig. x. Arthrobacter crystallopoietes was grown in various media, with growth assessed by the increase in absorbance at $485 \mathrm{~nm}: \square$, tryptone, glucose and yeast (TGY) broth; $\bullet, 0.5 \%$ L-asparagine with minimal salts (AMS); $\bigcirc, 0.5 \%$ succinate with minimal salts (SMS); $0.0 .5 \%$ glucose with minimal salts (GMS). Morphological changes are described and drawn as viewed by light microscopy on preparations stained with $0.1 \%$ methylene blue.

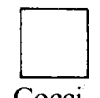

Cocci

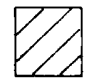

Elongating cocci and short rods

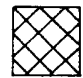

Rods

Fragmenting rods

\section{A}

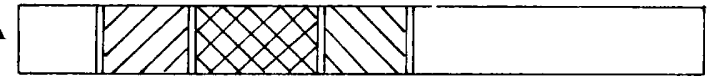

B

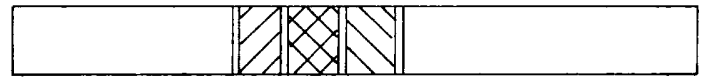

$\mathrm{C}$

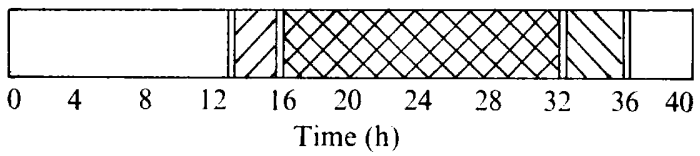

Fig. 2. Inhibitory effects of either $3^{\prime}: 5^{\prime}$-cyclic AMP or theophylline added at the beginning of the 'life-cycle' (time $=0$ ) to bacteria treated with Tris/EDTA (Leive, I965). A, Morphogenic cycle of control cells grown in SMS, AMS, TGY with or without the Tris/EDTA treatment; B, inhibition by I mM to $5 \mathrm{mM}-3^{\prime}: 5^{\prime}$-cyclic AMP in the same media; C, inhibition due to addition of $10 \mathrm{~mm}$ theophylline in the same media. 
Theophylline inhibits the phosphodiesterase specific for cyclic AMP and, furthermore, inhibits, in vitro, the phosphodiesterase isolated from Serratia marcescens (Okabayashi \& Ide, 1970). It was used in these experiments to maintain intracellular cyclic AMP levels during the morphogenic cycle. In the presence of 10 mM-theophylline, cells grown in GMS remained coccoidal and grew at the same rate as the control.

Theophylline delayed rod formation approximately 2 to $6 \mathrm{~h}$. Once rods were formed they failed to fragment and revert to cocci until $36 \mathrm{~h}$ whereas controls without theophylline fragmented at 18 to $22 \mathrm{~h}$ (Fig. 2). When theophylline was added to Tris/EDTA treated bacteria which had already reached the rod stage, fragmentation was delayed for 2 to $6 \mathrm{~h}$. The rods then fragmented and reverted to cocci.

\section{DISCUSSION}

Our observations indicate that exogenous cyclic AMP inhibits the normal initiation of the morphogenic event of elongation of cocci to rods in the life-cycle of Arthrobacter crystallopoietes and that theophylline has a similar effect, as well as causing a long delay in the process of fragmentation of rods to cocci. No effect was observed as a result of exogenous cyclic GMP in these experiments. This does not imply, however, that this nucleotide does not have a possible regulatory function, as yet undetermined, during the morphogenic cycle.

\section{REFERENCES}

CAmpos, J. M. \& ZustMAN, D. R. (1974). $3^{\prime}: 5^{\prime}$ cAMP: a trigger for differentiation in Myxococcus xanthus. Abstracts of 74th Meeting of American Society for Microbiology, Chicago, Illinois, p. 32. Washington: American Society for Microbiology.

CLARK, J. B. (I 972). Morphogenesis in the genus Arthrobacter. Critical Reviews of Microbiology I, 52 I-544.

Ensign, J. C. \& RitTenberG, S. C. (I963). A crystalline pigment produced from 2-hydroxypyridine by Arthrobacter crystallopoietes n. sp. Archiv für Mikrobiologie 47, I37-I 53.

Ensign, J. C. \& WolfE, R. S. (I964). Nutritional control of morphogenesis in Arthrobacter crystallopoietes. Journal of Bacteriology 87, 924-932.

LeIvE, L. (1965). Actinomycin sensitivity in Escherichia coli produced by EDTA. Biochemical and Biophysical Research Communications 18, 13-15.

Luscombe, B. M. \& Gray, T. R. G. (1971). Effects of varying growth rate on the morphology of Arthrobacter. Journal of General Microbiology 69, 433-434.

Luscombe, B. M. \& GRAY, T. R. G. (I974). Characteristics of Arthrobacter growing in continuous culture. Journal of General Microbiology 82, $213-222$.

OkABAYASHI, T. \& IDE, M. (1970). Cyclic $3^{\prime}: 5^{\prime}$-nucleotide phosphodiesterase of Serratia marcescens. Biochimica et biophysica acta 220 , I $16-123$.

Pastan, I. \& Pearlman, R. L. (I968). Regulation of $\beta$-galactosidase synthesis in Escherichia coli by cAMP. Journal of Biological Chemistry 234, 5420-5427.

Rickenberg, H. V. (1974). Cyclic AMP in procaryotes. Annual Review of Microbiology 28, 353-369.

Shapiro, L., Agabian-Keshishian, N., Hirsh, A. \& Rosen, O. M. (1972). Effect of dibutyryladenosine $3^{\prime}: 5^{\prime}$-cyclic nucleotide on growth and differentiation in Caulobacter crescentus. Proceedings of the National Academy of Sciences of the United States of America 69, 1225-I 229.

Yокота, T. \& Gots, J.S. (1970). Requirement of adenosine $3^{\prime}: 5^{\prime}$-cyclic phosphate for flagella formation in Escherichia coli and Salmonella typhimurium. Journal of Bacteriology 103, 513-5I 6. 